\title{
Competências Profissionais de Professores de Matemática do Ensino Médio Valorizadas por uma Boa Escola: a supremacia da cultura da performatividade
}

\section{Professional Skills of High School Mathematics Teachers Valued by a Good School: the supremacy of the culture of performativity}

\author{
Vanessa Franco Neto* \\ Marcio Antonio da Silva**
}

\begin{abstract}
Resumo
Este artigo apresenta alguns resultados de uma pesquisa realizada em uma escola que obteve um ótimo desempenho no ENEM/2009. Os principais objetivos foram investigar e analisar quais competências profissionais de professores de Matemática do ensino médio são consideradas relevantes por essa instituição de ensino e qual a influência da cultura da performatividade no trabalho desses docentes. Para isso, entrevistamos a coordenadora, a supervisora e os quatro professores do ensino médio da instituição investigada. Verificamos que as competências mais valorizadas são influenciadas diretamente pela necessidade de obtenção de bons resultados em avaliações internas e

\footnotetext{
* Mestre em Educação Matemática pela Universidade Federal de Mato Grosso do Sul (UFMS). Tutora a Distância do curso de Matemática (EaD/UFMS). Professora da Universidade Federal de Mato Grosso do Sul (UFMS) e da Universidade Anhanguera (Uniderp). Campo Grande, MS, Brasil. Membro do GP100 (GPCEM - Grupo de Pesquisa Currículo e Educação Matemática). Endereço para correspondência: Cidade Universitária, Caixa Postal 549, CEP: 79070-900, Campo Grande, MS, Brasil. E-mail: vanessaneto@ rocketmail.com.

*** Doutor em Educação Matemática pela Pontifícia Universidade Católica de São Paulo (PUC/SP). Professor do Centro de Ciências Exatas e Tecnologia, do Programa de Pós-Graduação em Educação Matemática e do Programa de Pós-Graduação em Educação da Universidade Federal de Mato Grosso do Sul (UFMS), Campo Grande, MS, Brasil. Líder do GP100 (GPCEM - Grupo de Pesquisa Currículo e Educação Matemática). Endereço para correspondência: Cidade Universitária, Caixa Postal 549, CEP: 79070-900, Campo Grande, MS, Brasil. E-mail: marcio.silva@ufms.br.
} 
externas. São elas: administrar o tempo, manter-se atualizado quanto às avaliações externas e relacionar-se bem com os alunos. Também constatamos que boa parte das ações da equipe gestora consiste em alinhar o corpo docente, objetivando a aprovação de seus estudantes nos mais concorridos exames vestibulares do país.

Palavras-chave: Educação Matemática. Formação de Professores de Matemática. Competências Profissionais. Cultura da Performatividade. Avaliações em Larga Escala.

\begin{abstract}
This article presents some results of research conducted in a school that had excellent results in the 2009 ENEM Exam (National Examination of High School Education). The main aims were to investigate and analyze what professional skills for mathematics teachers in high school are considered relevant for this institution. We also aimed to identify the influence of the culture of performativity in the work of these teachers. We interviewed the coordinator, supervisor and four high school teachers from the institution investigated. Our research showed that the most valued skills are directly influenced by the need to obtain good results in internal and external evaluations. The most valued skills were time management, keeping up to date with external evaluations and relating well to students. Another aspect we noticed about the management team was how the faculty aimed to ensure that their students were prepared for the most competitive entrance examinations in the country.
\end{abstract}

Keywords: Mathematics Education. Mathematics Teacher Education. Professional Skills. Culture of Performativity. Large-Scale Evaluations.

\title{
1 Delineando um cenário recorrente nos últimos anos
}

Segunda-feira, 19 de julho de 2010. Nessa data, o Instituto Nacional de Estudos e Pesquisas Educacionais (Inep) divulgou os resultados do Exame Nacional do Ensino Médio (ENEM), relativo ao ano de 2009. Em poucos minutos, a imprensa recebeu os dados do Inep, colocou os resultados das escolas em ordem decrescente e divulgou um ranking com a classificação geral por Estados, e até por municípios, das instituições de ensino que participaram de tal exame.

A partir de então, repórteres de várias mídias passaram a produzir e divulgar reportagens que enfatizavam o segredo do sucesso das escolas mais bem-sucedidas no ENEM, como se o bom resultado das instituições nesse exame fosse um atestado de qualidade do ensino médio, emitido pelo Governo Federal.

Essa ansiedade de buscar modelos que possam ser copiados em outros contextos parece fazer parte da natureza humana, representando uma forma 
ingênua de encontrar padrões de sucesso, não levando em conta as especificidades das milhares de instituições de ensino espalhadas por um país com dimensões continentais como é o caso do Brasil.

Os resultados que trazemos neste artigo são um recorte da pesquisa de Mestrado da primeira autora (NETO, 2011), orientada pelo segundo autor, no Programa de Pós-Graduação em Educação Matemática da Universidade Federal de Mato Grosso do Sul.

A investigação emergiu da curiosidade em conhecer os professores de Matemática que trabalham nas instituições que lideram esses rankings. Quem são esses professores? Quais competências profissionais desses professores são mais valorizadas pela equipe gestora da escola? Como o trabalho deles é influenciado pela necessidade de obter resultados excelentes em avaliações externas?

\section{Questões e objetivos da pesquisa}

A partir das mais variadas questões que surgiram, algumas delas enunciadas no tópico anterior, optamos por desenvolver nossa pesquisa investigando quais competências profissionais dos professores de Matemática são consideradas relevantes por determinados segmentos de uma escola (gestores e os próprios professores) bem classificada no Exame Nacional do Ensino Médio (ENEM), no ano de 2009, pois tínhamos como objetivo compreender como esses resultados influenciam o professor de Matemática na constituição de suas competências profissionais.

Ao buscarmos uma escola que tivesse atingido resultados significativos em avaliações externas, encontramos, no ranking de classificação das escolas no ENEM 2009, uma instituição de ensino localizada na cidade de Campo Grande - MS, onde os autores da pesquisa residem. Interessamo-nos pela escola em questão, pois ela obteve um resultado muito significativo em âmbito nacional, alcançando posição entre as dez melhores classificadas do país.

Utilizamos itálico para nos referirmos ao adjetivo boa, pois essa é uma qualificação que não foi atribuída por nós, mas, sim, adquirida pela escola no âmbito sociopolítico no qual está inserida. Não faz parte dos nossos objetivos investigar as razões que permitiram que a instituição recebesse tal qualificação, mesmo porque os pesquisadores não compartilham da referida adjetivação feita. Todavia, existe uma validação social quanto às práticas de gestão empreendidas na instituição, que são bem vistas pela sociedade em geral. 
É importante destacar que o ranking dos resultados do ENEM não faz parte dos objetivos do Governo Federal e não é estabelecido por ele. Essa listagem é organizada e divulgada pelos órgãos de imprensa nacional e a forma como essa divulgação é feita já foi comentada no início deste artigo.

Após essas constatações e discussões iniciais, chegamos à elaboração de nossas questões de pesquisa, a fim de que elas nos auxiliem a compreender todas as peculiaridades existentes nessa unidade escolar:

(i) Quais as competências profissionais de professores de Matemática do ensino médio são consideradas relevantes por uma escola destacada em avaliação externa?

(ii) Qual a influência da cultura da performatividade na constituição das competências profissionais desse professor?

Os dados para a construção de nossa pesquisa foram obtidos mediante entrevistas com quatro professores de Matemática, uma coordenadora e uma supervisora, atuantes no ensino médio da instituição pesquisada.

A fim de nortearmos nossa investigação rumo às possíveis respostas aos nossos questionamentos, elaboramos nossos objetivos:

(i) delinear as competências profissionais de professores de Matemática do ensino médio que são consideradas relevantes por uma escola com ótimo desempenho no ENEM 2009;

(ii) verificar como a cultura da performatividade influencia o trabalho dos professores de Matemática do ensino médio que atuam em uma escola de excelência.

Para nos auxiliar a responder nossas questões e alcançar nossos objetivos, utilizamos dois aportes teóricos, detalhados nos próximos tópicos: as competências profissionais e a cultura da performatividade.

\section{As competências profissionais de professores}

Quando tratamos de competências profissionais, no âmbito da formação de professores, um nome citado recorrentemente é o do pesquisador Philippe Perrenoud, um dos mais expressivos promotores do termo e de sua aplicabilidade quando inserido no contexto da educação. Ele define competência como "a capacidade de mobilizar diversos recursos cognitivos para enfrentar um tipo de situação" (PERRENOUD, 2000, p. 15).

De acordo com ele, competência profissional também é:

[...] um conjunto diversificado de conhecimentos da 
profissão [docente], de esquemas de ação e de posturas que são mobilizadas no exercício do ofício. De acordo com esta definição bem ampla, as competências são, ao mesmo tempo, de ordem cognitiva, afetiva, conativa e prática (PERRENOUD et al. 2001, p. 12).

Em outra obra, o pesquisador clarifica o conceito de competência, argumentando que se trata de

[...] aptidão para enfrentar uma família de situações análogas, mobilizando de uma forma correta, rápida, pertinente e criativa, múltiplos recursos cognitivos: saberes, capacidades, microcompetências, informações, valores atitudes, esquemas de percepção, de avaliação e de raciocínio (PERRENOUD, 2002, p. 19).

As orientações para a formação de professores no Brasil têm se fundamentado, entre outros conceitos, no de competência profissional. A ênfase nesse conceito, como sendo nuclear na organização curricular da formação docente, acentuou-se a partir de 1996, ano da promulgação da Lei de Diretrizes e Bases da Educação Nacional ${ }^{1}$.

Perrenoud (2000) relacionou dez famílias de competências, classificandoas como prioritárias na formação de professores: (i) organizar e dirigir situações de aprendizagem; (ii) administrar a progressão das aprendizagens; (iii) conceber e fazer evoluir os dispositivos de diferenciação; (iv) envolver os alunos em suas aprendizagens e em seu trabalho; (v) trabalhar em equipe; (vi) participar da administração da escola; (vii) informar e envolver os pais; (viii) utilizar novas tecnologias; (ix) enfrentar os deveres e os dilemas éticos da profissão; (x) administrar sua própria formação continuada.

Neste recorte de pesquisa, limitaremos nossas análises a três famílias de competências (ii, vii e x) e investigaremos como essas são valorizadas ou desvalorizadas pelos professores e pela equipe gestora da escola ou, ainda, quais outras competências emergem a partir das análises das transcrições das entrevistas feitas com os participantes ${ }^{2}$ da pesquisa.

\footnotetext{
${ }^{1}$ Não discutiremos, neste artigo, as críticas ao conceito de competências, mas o leitor pode consultar alguns artigos e livros que discorrem sobre o tema. Entre eles: Sacristán et al. (2011), Dias e Lopes (2003).

${ }^{2}$ Optamos por utilizar o termo participantes, ao invés de sujeitos, assim como recomenda Yin (2011) ao se referir aos indivíduos que aceitam participar de estudos qualitativos.
} 
Segue-se uma breve descrição dessas três famílias de competências, na concepção de Perrenoud (2001).

Ao sugerir a administração da progressão das aprendizagens, Perrenoud (2001) abarca a necessidade de produção de um ensino estratégico, no qual deveriam ser considerados os objetivos do ensino, as limitações e potencialidades dos alunos, as avaliações periódicas das inferências e dos resultados obtidos pelo professor e uma visão longitudinal do ensino, promovendo a continuidade dos assuntos tratados. Portanto, essa competência está relacionada ao gerenciamento das atividades de ensino.

Ao evocar a participação dos pais no desenvolvimento dos saberes de seus filhos, o pesquisador atribui à responsabilidade dos pais de educarem seus filhos uma importância tão grande quanto à dos professores de instruírem seus alunos. Nesse caso, a competência requerida do professor seria a de propor acordos entre o programa da escola e as convicções pedagógicas e sociais dos pais, aceitando-os como eles são, em sua diversidade e chamando-os a colaborarem para o sucesso escolar dos seus filhos.

Importante ressaltar que os pais, ao matricularem seus filhos em determinada instituição, concordam com a proposta pedagógica apresentada pela escola. Portanto, há um contrato implícito e, muitas vezes, uma das cláusulas mais valorizadas é garantir a aprovação do estudante nos mais concorridos exames vestibulares.

Perrenoud (2001) argumenta que, para administrar sua própria formação continuada, o professor necessita de constante aperfeiçoamento profissional, independentemente do apoio dado pela instituição de ensino na qual ele trabalha.

Além de participar de cursos, a reflexão sobre a própria prática e a troca de experiências entre os pares também fazem parte dessa família de competências, podendo colaborar com o aprimoramento profissional. Para o pesquisador, as trocas de experiências entre professores podem trazer grandes contribuições para o trabalho docente.

A partir dessas três famílias de competências, procuramos algumas similaridades na fala dos professores e gestores que pudessem caracterizá-las. Além disso, buscamos encontrar traços que revelassem a influência da busca exagerada por bons resultados em avaliações externas no trabalho do professor, o que configura traços da cultura da performatividade. Pretendemos elucidar tal expressão no próximo tópico, trazendo contribuições importantes e pouco utilizadas na Educação Matemática brasileira. 


\section{A cultura da performatividade}

Santos (2004) afirma que as atuais políticas educacionais que apoiam as avaliações em larga escala acabam evidenciando uma nítida diferenciação de desempenho entre os estabelecimentos de ensino frequentados por estudantes das classes sociais alta e baixa. Segundo a autora, a mesma divisão de classes gerada pelo poder aquisitivo das famílias é reproduzida no setor educacional, evidenciando uma grande desigualdade, que resulta em um ensino voltado às elites e outro voltado aos mais pobres.

Desse modo, "se delineia uma nova arquitetura para o setor educacional, edificada a partir de critérios de eficiência e eficácia em consonância com os interesses de mercado" (SANTOS, 2004, p. 1146). Assim, aos moldes da cultura do desempenho e da qualidade medida pela relação entre investimento e eficiência, observa-se a absorção de elementos de mercado pelos sistemas de educação.

A cultura de desempenho remodela as formas de trabalho dos profissionais da área educacional. Santos (2004) nota que a grande motivação dos professores imersos nessa cultura está ligada à obtenção de bons resultados dos seus alunos em avaliações em larga escala e não a proporcionar ao seu aluno uma educação de qualidade que vise à formação de um cidadão crítico, preocupado com a transformação social e com a melhoria das condições de vida da comunidade na qual ele está inserido.

O pesquisador da Universidade de Londres, Stephen J. Ball, sociólogo e principal divulgador da expressão cultura da performatividade, argumenta que o setor educacional é influenciado pelos movimentos que regem as tendências atuais de organização da sociedade e sua relação com o trabalho.

De acordo com Lopes e Macedo (2011, p. 245), o objetivo do pesquisador inglês é "investigar as políticas de maneira que o compromisso com a eficiência e os resultados instrucionais não sejam considerados em detrimento do compromisso com a justiça social". Tal interpretação dos trabalhos do pesquisador pode ser compreendida quando, no excerto a seguir, Ball justifica seus posicionamentos acerca dos temas que trata. Segundo ele:

Cada vez mais, as políticas sociais e educacionais estão sendo articuladas e legitimadas explícita, direta e, muitas vezes, exclusivamente em função do seu papel em aumentar a competitividade econômica por meio do desenvolvimento de habilidades, capacidades e disposições exigidas pelas novas formas econômicas da alta modernidade. [...] Almejados e celebrados por quase todos os Estados das 
sociedades ocidentais, os valores e incentivos das políticas de mercado legitimam e dão impulso a certos compromissos e ações - empreendimentos, competição, excelência - ao mesmo tempo que inibem e deslegitimam outros - justiça social, equidade, tolerância (BALL, 2004, p. 1109 e 1122).

Dessa maneira, o autor apresenta indícios do culto a esse processo de organização social na educação. Ball (2005) trata da instauração desse modelo nos setores privados da sociedade e define o termo performatividade, compreendendo-o no contexto da atual sociedade econômica.

A performatividade é uma tecnologia, uma cultura e um método de regulamentação que emprega julgamentos, comparações e demonstrações como meios de controle, atrito e mudança [...] A performatividade é alcançada mediante a construção e publicação de informação e de indicadores, além de outras realizações e materiais institucionais de caráter promocional, como mecanismo para estimular, julgar e comparar profissionais em termos de resultados: a tendência para nomear, diferenciar e classificar (BALL, 2005, p. 543-544).

Os estudiosos que se preocupam em investigar a influência dessa cultura na sociedade buscam compreender os mecanismos que a constituem. Para nós interessava encontrar os efeitos dessa tendência na instituição pesquisada.

Mais especificamente, estávamos empenhados em saber como essa cultura atinge gestores e professores de Matemática do ensino médio e como eles se posicionam frente a essa cultura.

Além da preocupação, em termos das exigências feitas aos alunos e que os conduzem a buscar, quase que exclusivamente, os resultados em avaliações externas e internas, outra preocupação com essa tendência é que a atuação dos professores pode tornar-se limitada.

Ao profissional que atua em meio a esses propósitos cabe apenas a execução das ordens que lhes são dadas. Espera-se que, nessa execução, sejam efetivamente realizadas todas as incumbências preestabelecidas pela equipe gestora. Não há espaço para a criatividade. Impera a homogeneização de processos de ensino, até mesmo com relação à forma de tratamento dos alunos.

Todavia, verificamos que esse posicionamento é, também, uma exigência social, pois a comunidade escolar valoriza os bons resultados, mesmo não conhecendo bem os instrumentos que os geraram. 
Ball (2005, p. 541) afirma que, em meio a essa tendência, "o profissionalismo só tem significado dentro da moldura de uma racionalidade substantiva, e as tentativas de redefinir o profissionalismo dentro de uma estrutura dominada pela racionalidade técnica tornam esse termo sem sentido".

Em meio à cultura da performatividade, Ball ainda afirma que, para atender às objetividades do modelo, há de se admitir que "a eficácia só existe quando é medida e demonstrada, e as circunstâncias locais só existem como desculpa inaceitável para falhas na execução ou na adaptação" (BALL, 2005, p. 543).

Assim, para um professor que esteja atuando em sala de aula, nas instituições que atendem às especificidades dessa tendência (cultura da performatividade), não cabe avaliar e julgar as necessidades de seus alunos e fazer com que sua atividade adquira um sentido no referido contexto no qual está inserido. Cabe a ele, para ser considerado um bom profissional, cumprir o programa preestabelecido e encontrar os meios que proporcionem aos seus alunos a assimilação desses conteúdos.

Nossa pesquisa também objetivou encontrar traços dessa cultura na fala de professores e gestores, e verificar se surgem novas competências que representam um antagonismo em relação às competências profissionais citadas no tópico anterior.

\section{Características da pesquisa, da escola e dos participantes analisados}

Esta investigação é caracterizada como uma pesquisa qualitativa, na modalidade estudo de caso.

É qualitativa por, dentre várias características, contemplar as cinco principais elencadas por Bogdan e Biklen (1994): (i) a pesquisa qualitativa tem o ambiente natural como sua fonte direta de dados e o pesquisador como seu principal instrumento; (ii) os dados coletados são predominantemente descritivos; (iii) a preocupação com o processo é muito maior do que com o produto; (iv) a análise dos dados tende a seguir um processo indutivo e (v) o significado que os participantes da pesquisa dão às coisas e à sua vida são focos de atenção especial do pesquisador.

É um estudo de caso devido às propriedades significativamente peculiares da escola a qual nos propusemos investigar. A escolha pela referida instituição deu-se por ser uma das instituições mais bem classificadas no ranking do ENEM de 2009, figurando entre as dez escolas com melhor desempenho no Brasil. 
Yin (2005, p. 63) lista cinco fundamentos lógicos para um caso único. Classificamos nosso caso como sendo o terceiro elencado por esse pesquisador: quando temos um caso representativo ou típico. O objetivo é investigar um caso que seja representativo dentro de um conjunto de casos similares. Para o autor, "parte-se do princípio de que as lições que se aprendem desses casos fornecem muitas informações sobre as experiências da pessoa ou instituição usual".

Dessa maneira, entendemos que a escola investigada representa o que ocorre em boa parte das instituições de ensino que obtêm resultados significativos em avaliações externas no Brasil.

A escola investigada se localiza na cidade de Campo Grande, no Estado de Mato Grosso do Sul. Trata-se de uma instituição privada de ensino que possui uma boa infraestrutura e oferece desde a educação infantil até o terceiro ano do ensino médio. Também, disponibiliza aos seus estudantes a opção de realizarem um curso pré-vestibular.

Os alunos que se candidatam a ingressar na instituição passam por uma avaliação para verificar se possuem conhecimentos mínimos para frequentar as aulas. As gestoras relataram que, em geral, os que não obtêm um bom resultado nessa avaliação preliminar não são prontamente rejeitados. O procedimento é alertar os pais acerca das dificuldades que eles poderão enfrentar e, também, da necessidade de maior dedicação por parte desse aluno para que ele não tenha rendimento abaixo do que seria considerado o mínimo para a progressão para a série seguinte.

Todos os entrevistados relataram que a escola se insere no perfil de instituição tradicional e, na visão deles, esse adjetivo define uma estrutura na qual impera o respeito ao professor, ou seja, ele sempre tem razão frente ao aluno.

O ensino centra-se na concepção mecanicista, ou seja, boa parte das ações docentes está ligada ao ensino de técnicas que devem ser utilizadas no menor tempo possível. Para os profissionais que entrevistamos, essa ênfase no treinamento é a melhor maneira de conduzir os alunos à aprendizagem dos conteúdos que podem ser cobrados no vestibular.

O destacado resultado do ENEM foi obtido pelos alunos que cursavam o terceiro ano em 2009. Esse grupo era formado por apenas dezessete alunos.

As entrevistas foram realizadas com a supervisora, a coordenadora pedagógica e os quatro professores de Matemática do ensino médio.

O quadro 1, apresentado a seguir resume as principais informações a respeito dos entrevistados: 


\begin{tabular}{|l|l|c|l|l|}
\hline $\begin{array}{l}\text { Cargo ocupado } \\
\text { na escola }\end{array}$ & Gênero & $\begin{array}{c}\text { Identificação } \\
\text { na pesquisa }\end{array}$ & $\begin{array}{l}\text { Tempo de experiência de } \\
\text { magistério, coordenação } \\
\text { e/ou supervisão }\end{array}$ & \multicolumn{1}{|c|}{ Formação Acadêmica } \\
\hline Supervisora & Feminino & S & $\begin{array}{l}\text { 25 anos, sendo 23 anos na } \\
\text { escola pesquisada. Desses 23 } \\
\text { anos, 2 como supervisora. }\end{array}$ & $\begin{array}{l}\text { Licenciatura e Mestrado em } \\
\text { Geografia }\end{array}$ \\
\hline $\begin{array}{l}\text { Coordenadora } \\
\text { Pedagógica }\end{array}$ & Feminino & C & $\begin{array}{l}19 \text { anos, sendo 7 anos na } \\
\text { escola pesquisada. Desses 7 } \\
\text { anos, 2 como coordenadora. }\end{array}$ & $\begin{array}{l}\text { Licenciatura em Educação } \\
\text { Artística. } \\
\text { Especialização em } \\
\text { Psicopedagogia }\end{array}$ \\
\hline $\begin{array}{l}\text { Professor de } \\
\text { Matemática }\end{array}$ & Masculino & MC & $\begin{array}{l}12 \text { anos, sendo 1 ano na } \\
\text { escola pesquisada. }\end{array}$ & $\begin{array}{l}\text { Licenciatura em } \\
\text { Matemática. }\end{array}$ \\
\hline $\begin{array}{l}\text { Professor de } \\
\text { Matemática }\end{array}$ & Masculino & VA & $\begin{array}{l}13 \text { anos, sendo 4 na escola } \\
\text { pesquisada. }\end{array}$ & $\begin{array}{l}\text { Licenciatura e Bacharelado } \\
\text { em Matemática Aplicada e } \\
\text { Computacional. }\end{array}$ \\
\hline $\begin{array}{l}\text { Professor de } \\
\text { Matemática }\end{array}$ & Masculino & SA & $\begin{array}{l}4 \text { anos e meio na escola } \\
\text { pesquisada }{ }^{3} .\end{array}$ & $\begin{array}{l}\text { Licenciatura e Bacharelado } \\
\text { em Matemática Aplicada e } \\
\text { Computacional. }\end{array}$ \\
\hline $\begin{array}{l}\text { Professora de } \\
\text { Matemática }\end{array}$ & Feminino & MO & $\begin{array}{l}\text { Licenciatura em Ciências } \\
\text { com Habilitação em } \\
\text { escola pesquisada. }\end{array}$ & $\begin{array}{l}\text { Matemática. } \\
\text { Pós-Graduação em } \\
\text { Tecnologia. }\end{array}$ \\
\hline
\end{tabular}

Quadro 1 - Resumo das informações sobre os participantes da pesquisa analisados

O objetivo inicial era realizar duas entrevistas com cada participante pesquisado. Como as entrevistas foram semiestruturadas, algumas delas suscitaram novos encontros para o esclarecimento e o aprofundamento de assuntos levantados.

Ao todo foram quatorze entrevistas, cada uma com duração média de quarenta minutos, todas feitas nas dependências da própria escola analisada.

Todas as entrevistas foram transcritas para que fosse iniciado o processo de análise, detalhado no tópico a seguir.

\section{Análise das transcrições das entrevistas}

As análises das transcrições das entrevistas realizadas foram feitas por intermédio do processo de categorização.

Ao construirmos o roteiro das entrevistas, pretendíamos relacionar as respostas dos nossos entrevistados às dez famílias de competências citadas por Perrenoud (2000) e já citadas nesse artigo. Portanto, pretendíamos realizar uma categorização a priori.

No entanto, algumas categorias emergiram da análise feita, inclusive

\footnotetext{
${ }^{3} \mathrm{O}$ professor SA começou a trabalhar nessa escola quando ainda não havia concluído seu curso de licenciatura.
} 
representando um total antagonismo em relação às categorias mencionadas por Perrenoud. Dessa forma, optamos pelo tipo de categorização que Fiorentini e Lorenzato (2007, p. 135) chamam de mista: "quando o pesquisador obtém as categorias a partir de um confronto entre o que diz a literatura e o que encontra nos registros de campo".

As quatro categorias que representam competências profissionais valorizadas pelas gestoras e pelos próprios professores da instituição pesquisada, e que surgiram a partir das análises, foram: (i) administrar o tempo; (ii) relacionarse bem com os alunos; (iii) manter-se atualizado quanto às avaliações; (iv) utilizar bem o material didático. Neste artigo, nos limitaremos à análise das três primeiras.

As análises apresentadas mostram que essas competências vêm de encontro com algumas citadas por Perrenoud, expressando justamente ideias contrárias àquelas que o pesquisador suíço concebeu ao listar suas dez famílias de competências.

\subsection{Administrar o tempo versus administrar a progressão das aprendizagens}

Como já vimos, Perrenoud (2000) se refere à administração da progressão das aprendizagens, levando em conta a necessidade de produzir atividades de ensino que se adaptem à peculiaridade de cada estudante.

Isso faz com que seja imprescindível retomar objetivos de ensino, inserir novos temas, excluir outros, reformular a estrutura organizacional do currículo, realizar avaliações periódicas, entre outras ações que demandam tempo.

$\mathrm{Na}$ instituição de ensino pesquisada, essas ações seriam consideradas como sendo sinônimo de atraso e incompetência.

A coordenadora do ensino médio salienta que a questão do tempo é fiscalizada até pelos estudantes, os quais podem relatar se a rotina esperada pelos gestores para as aulas está sendo cumprida de maneira adequada. Os alunos do ensino médio respondem periodicamente a um questionário que avalia o professor:

C - Ela não é uma avaliação onde você pergunta: o professor é legal?. Não, são perguntas onde, é feito assim: os exercícios condizem com a aula?, o tempo de exercícios condiz com a aula?, as questões cobradas em prova são coerentes com a aula dada pelo professor? Então, a gente vai e volta nas perguntas, que não tem como o aluno ser diretamente contra aquele professor, ele está 
falando sobre o geral, o trabalho daquela disciplina. Então, a gente leva as perguntas para esse lado: cumpre o conteúdo no prazo certo? Essas coisas assim: aproveita a aula cem por cento?,dá tarefa?, cobra tarefa?, faz perguntas difíceis ou só fáceis?, então a gente vai fazendo com que o aluno esqueça a figura professor $e$ se lembre do momento aula.

Sobre a administração do tempo, um dos professores relata que o fato de levar os alunos ao laboratório de informática pode significar perda de tempo: $S A-E$, tem o laboratório [de informática], mas eu, eu sinceramente nunca usei. [...] Então o tempo que eu desloco para subir, para ligar computador, para tal e para descer, eu podia estar resolvendo exercício, entendeu?

Uma das formas para otimizar o tempo das aulas nessa escola é dividir os alunos de acordo com o desempenho deles em avaliações periódicas realizadas internamente. Dessa maneira, as turmas são divididas segundo a nota dos estudantes nessas provas. Os melhores classificados formam a sala $A$, o segundo bloco de alunos compõe a sala $B$, e assim por diante.

Sobre a existência de divisão de salas, a coordenadora pedagógica do ensino médio justifica tal fato pelo melhor rendimento da aula:

C-Qual é o objetivo da sala A? Os professores são os mesmos, a prova é a mesma, a carga horária é a mesma, só que eu tenho ali, alunos mais ou menos no mesmo nível. Então rende mais em exercício [...].

Mesmo assim, é inevitável ter que lidar com as diferenças de desempenho entre os estudantes. Para tentar padronizar ainda mais as aulas, os alunos são encaminhados para o chamado plantão de dúvidas, onde eles podem ter as suas dúvidas dirimidas.

MC - Então, essa questão de retornar a atividade para eles, fica um pouco complicada no terceiro ano e no cursinho. Por quê? Porque como eu te falei, nós temos um problema sério que é o tempo. Duas aulas ${ }^{4}$ para cumprir a carga horária é um tempo muito ínfimo para você poder voltar naquele conteúdo que passou, que você viu que ele não aprendeu. Então, como é que a gente pode suprir

\footnotetext{
${ }^{4}$ Há cinco aulas semanais de Matemática no ensino médio dessa escola. Essas aulas são divididas em duas frentes: Álgebra, com três aulas semanais, e Geometria, com duas. Cada frente é ministrada por um professor diferente. Dessa maneira, o professor MC leciona apenas Geometria. Portanto, ele tem apenas duas aulas semanais em cada turma.
} 
isso? Num trabalho que nós fazemos que é o plantão de dúvida.

$\mathrm{O}$ mesmo professor se refere a uma verdadeira corrida contra o tempo para cumprir o conteúdo, mesmo em detrimento do aprendizado dos alunos. A ênfase é a preparação para os exames vestibulares. Dessa maneira, a aula é vista como um treino de um atleta para participar de uma maratona.

MC - Nós trabalhamos com uma aula ainda reduzida [referindo-se aos quarenta e cinco minutos de tempo de aula]. Você vê: eu tenho duas aulas, eu tenho noventa minutos para cumprir todo o conteúdo de Geometria. No caso de Geometria, no meu ponto de vista, eu acho muito pouco. Então não dá tempo de você trabalhar de uma forma diferente, assim no caso: ah, vamos fazer uma atividade diferente, em grupo então. Ou então: vamos propor que o aluno faça a atividade e vá para o quadro e, depois de terminada essa atividade, ele vai paro o quadro e corrige, vamos fazer a correção. Não dá tempo disso! Então eu trabalho nesse esquema: eu explico a teoria de um modo bem sucinto, resolvo dois, no máximo três exercícios e, o que sobra da aula, é o tempo que eu passo de exercício para eles resolverem e me entregarem.

Esses poucos trechos extraídos das transcrições das entrevistas feitas com os participantes da pesquisa revelam que o tempo deve ser administrado com eficiência, ou seja, deve-se cumprir o conteúdo no prazo predeterminado, sem levar em consideração as especificidades dos estudantes.

\subsection{Relacionar-se bem com os alunos versus informar e envolver os pais}

A competência de informar e envolver os pais, como já vimos, valoriza ações docentes que estimulam a participação e o envolvimento dos pais na vida escolar dos filhos.

Essa relação entre familiares e professores, a qual Philippe Perrenoud se refere, é alicerçada em uma harmonia entre as opiniões dos pais sobre o que é uma boa educação e a proposta pedagógica seguida pela escola. Desse modo, os possíveis conflitos advindos desse vínculo são resolvidos por intermédio de diálogos que tem o projeto pedagógico da escola como referência.

Se, por exemplo, a proposta da escola está alicerçada nas ideias construtivistas e o professor de Matemática ministra todas suas aulas seguindo a sequência - apresentação de definições, exposição de exemplos simples, resolução de exercícios e correção dos mesmos - os pais irão questioná-lo, pois 
o contrato pedagógico implícito não está sendo seguido.

No caso da escola investigada, a principal cláusula desse contrato é obter aprovação nos mais concorridos exames vestibulares do país. Isso inclui um olhar atento dos pais e gestores sobre os resultados obtidos em avaliações internas e externas. Sobre esse assunto, a supervisora revela quais as características de um bom professor de Matemática:

$S$ - Se eu fosse resumir pra você: qualidade de aula, qualidade do aprendizado desse aluno. Ele tem que garantir que esse aluno apreenda de verdade, através das avaliações, através do desempenho dos alunos nos vestibulares. Internamente, através da movimentação desse professor em sala de aula, através dos testes, através das avaliações, através dos simulados e através da avaliação institucional do professor que é feita por nós e pelos alunos. E, externamente, através da aprovação em vestibulares.

A opinião dos alunos referente a aspectos didático-pedagógicos do professor é levada em conta, mas é evidente que esses jovens não têm condição de analisar pedagogicamente o trabalho dos seus professores. Então, como eles são ouvidos? A escola dá voz a eles, assim como um prestador de serviços dá voz aos seus clientes, por intermédio de pesquisas de satisfação. A máxima do cliente tem sempre razão é seguida à risca:

$V A$ - Ah, isso [referindo-se à avaliação que os alunos fazem dos seus professores] é bom para o colégio saber quem [...] quem são os clientes são os alunos, não é? Então eles têm que estar satisfeitos e mostrar também para a gente mudar se não está [...] algum ponto está falho a gente tem que mudar, não é? Não pode ficar acomodado. Isso é importante.

Essa avaliação que, supostamente, mensura a qualidade da atuação docente é questionada apenas por uma professora:

MO - Porque um aluno, se ele tiver com raiva de você, ele não responde a seu favor. Se eles combinarem entre eles, eles detonam um professor, você concorda? [...] E outra coisa, o que um menino de dezesseis anos, quinze anos, pode dizer [a respeito da prática do professor]? Pode dizer que você não sabe?

Um termo recorrente utilizado pelas gestoras é o alinhamento. Esse alinhamento que a escola faz nos seus docentes está ligado a agradar os alunos, cumprir os conteúdos e garantir bons resultados dos estudantes em avaliações externas. 
Um docente menciona que a coordenação da escola se preocupa com a provável relação que os estudantes poderiam fazer entre bom professor e professor amigo, pois o fato de ser complacente não significa que os objetivos educacionais são atingidos:

SA - O grande medo da coordenação era que talvez eles [os alunos] confundissem a parte de ser legal, e talvez eles pudessem achar que ser legal é ser amigo, e tal. Mas eles [os alunos] conseguem dividir [distinguir] bem [entre o bom professor e o professor amigo]. Ainda sobre o alinhamento, a supervisora relata que a opinião e satisfação do estudante é um fator importante nas decisões administrativas da escola e reforça que a aprovação dos seus alunos nos exames vestibulares é o principal objetivo da instituição:

$S-(\ldots)$ de qualquer forma esse professor ele é alinhado. $O$ que é o alinhamento? Todas as vezes que se chama esse professor são apontadas referências de atuação para ele. Esse feedback é constante. Entretanto, se eu falo e se já foi apontado na avaliação do aluno, se foi continuamente apontada falhas na nossa avaliação e nada for feito por este profissional, dá-se um tempo. A escola sempre dá um tempo para esse profissional se alinhar, mas eu também prezo pelo meu aluno. Então o meu aluno não pode pagar pelo erro de um. Eu tenho a qualidade de muitos aqui, eu tenho vestibular pela frente, eu tenho um compromisso, tá?

Quase não encontramos menção aos pais, tanto nas transcrições das entrevistas das gestoras, quanto nas dos professores.

Mesmo sendo questionados sobre a participação dos pais na vida escolar dos seus filhos, todos os entrevistados afirmaram que os mesmos só são convidados a comparecerem à instituição caso haja problemas muito graves envolvendo seus filhos. Mesmo nesse caso, os professores são poupados do contato com os pais. A equipe gestora faz o máximo para evitar tal encontro.

Por outro lado, como evidenciam os fragmentos de transcrições mostrados neste tópico, a opinião dos alunos é supervalorizada, evidenciando uma relação que considera o aluno como um cliente da escola e, para sua satisfação, é exigido grande esforço, por parte do professor, para agradar sua clientela. 


\subsection{Manter-se atualizado quanto às avaliações versus administrar a própria formação continuada}

A competência de administrar sua própria formação continuada é uma das citadas por Philippe Perrenoud. Tanto o professor MC como VA não possuem nenhum tipo de formação complementar, além da graduação. Eles sustentam que não se envolvem com programas de formação continuada devido à elevada carga horária semanal de trabalho.

Já a professora MO participou de um programa de Pós-Graduação em Tecnologias na Educação em uma instituição de ensino superior privada. No entanto, ela nos esclarece que essa não foi uma experiência proveitosa:

MO - É, tecnologia. Mas eu diria que olha [...] só ficou no nome, porque de tecnologia eu não aprendi nada. Aliás, eu não sei, eu não aprendi nada na Pós.

Apenas o professor SA nos informou, à época da pesquisa, que estava cursando uma especialização em Educação Matemática, em uma instituição privada.

O fato dos professores não buscarem cursos de formação continuada também é justificado pela consequente redução do número de aulas semanais que eles teriam, caso optassem por realizar tais programas de estudo:

MC - Se eu for fazer o mestrado eu vou ter que diminuir minha carga horária, vamos dizer pela metade. Ou mais da metade. Quando eu terminar o mestrado e voltar para o colégio eu não vou ter mais essas minhas aulas. Eu tenho um colega também, o professor M. de Física, que é formado em Matemática, mas dá aula de Física, que ele também sente essa mesma dificuldade: como é que nós vamos fazer um mestrado se nós estamos nessa realidade? Então, assim, eu estou tentando me preparar pra poder fazer um mestrado. Três anos que eu estou nesse preparo aí, e eu vou adiando, vou adiando. [...] Por que eu estou precisando até, assim do mestrado, não é? Por que eu quero continuar, quero fazer na área de Educação Matemática. Por que hoje eu trabalho nessa área, não é?

A instituição se fecha para influências de tendências educacionais que levam em conta as pesquisas realizadas nos últimos anos. Essa blindagem é evidenciada no depoimento de um professor que relata um evento intitulado Semana Pedagógica que ocorre na semana que antecede o início do ano letivo. 
VA - A gente faz um trabalho na semana pedagógica, a gente tem que realizar uma apresentação. Alguns professores são voluntários para fazer uma palestra de acordo com o tema que ele vai escolher. E para esse ano eu fiz uma palestrinha, mas vários professores fizeram. Praticamente não vem quase ninguém de fora, fica entre nós mesmo. É bem bacana.

Esse evento é fechado para profissionais da própria escola e o objetivo principal é a divulgação e troca de boas experiências de ensino. No entanto, as discussões centralizam-se na otimização do uso do material didático utilizado pela instituição:

$C$ - Este ano nós tivemos a professora MO de matemática, o SA de matemática também, e a professora de Biologia, colocando para todos os professores como eles tiveram resultados positivos com o material [apostilado. Adotado pela escola, desde 2010, para todos os anos do ensino médio]. [...] A gente não precisa trazer gente de fora porque temos gente boa aqui.

Reforçando essa pretensa autossuficiência pedagógica da instituição, um dos docentes relata que precisa manter-se atualizado quanto às tendências dos exames vestibulares:

VA - E sempre focando o objetivo que é o vestibular, não é? Principalmente o vestibular. Procuro baixar as questões do vestibular, do assunto que estou tratando em sala. E falo: caiu no vestibular isso. [...] Aí tem que já ir acostumando com o tipo de questão que eles vão encarar.

O mesmo professor salienta que o objetivo fulcral do seu trabalho é fazer com que os seus alunos alcancem bons resultados em avaliações externas para promover a escola. Essa finalidade do ensino, na instituição, constitui uma exaltação da cultura da performatividade.

VA - Trabalhar em cima do que eles vão prestar, não é? Por que é o marketing, não é? É o marketing do colégio também. E, esse negócio da colocação do ENEM, nossa, alavancou o colégio [...] nesse nível social que o colégio atinge.

$\mathrm{Na}$ concepção do professor VA, para que um profissional seja considerado bem-sucedido, exercendo a docência na escola pesquisada, é preciso estar preparado para sanar todas as dúvidas dos alunos com relação às questões dos exames vestibulares que eles realizarão, incluindo as tendências específicas de cada prova. Sobre isso, ele afirma: 
VA - Tem que estar estudando essas provas que os meninos têm tendência a resolver. Essas provas da FGV, FUVEST, UNICAMP, UNESP, UEM, UEL, são provas que têm as questões de Matemática bem elaboradas. [...] Ele [o estudante] tem que estar antenado com as provas e com as tendências.

Portanto, a escola não se preocupa com a formação dos seus professores realizada fora da instituição. Pelo contrário, assume que os docentes devem preocupar-se apenas com a troca de informações entre eles, visando o bom uso do material disponível e, principalmente, com a atualização em relação às avaliações externas, identificando tendências que são consideradas informações valiosas e podem representar a diferença entre a aprovação e a reprovação dos seus estudantes.

\section{Considerações finais}

Nossas questões de pesquisa consistiram em discutir quais as competências profissionais são valorizadas no contexto de excelência da escola investigada e, também, como a cultura da performatividade influencia o trabalho dos docentes que lá atuam.

Ao final de nossa investigação, concluímos que as competências profissionais enfocadas neste artigo e elencadas por Philippe Perrenoud administrar a progressão das aprendizagens; informar e envolver os pais; administrar sua própria formação continuada - são pouco ou nada valorizadas por uma das instituições de ensino mais bem conceituadas em âmbito nacional, levando-se em conta os resultados de seus alunos em uma avaliação externa.

A partir da análise da valorização ou não dessas competências, verificamos que outras são extremamente valorizadas, tanto pela equipe gestora quanto pelos próprios professores de Matemática do ensino médio: administrar o tempo; relacionar-se bem com os alunos; manter-se atualizado quanto às avaliações.

Essas três competências que emergiram a partir da análise das transcrições, representaram um antagonismo em relação às outras três citadas por Philippe Perrenoud. A figura 1, apresentada a seguir, ilustra como esse processo antagônico, constituído por oposições de competências profissionais, é mediado pela supremacia da cultura da performatividade existente na instituição investigada. 


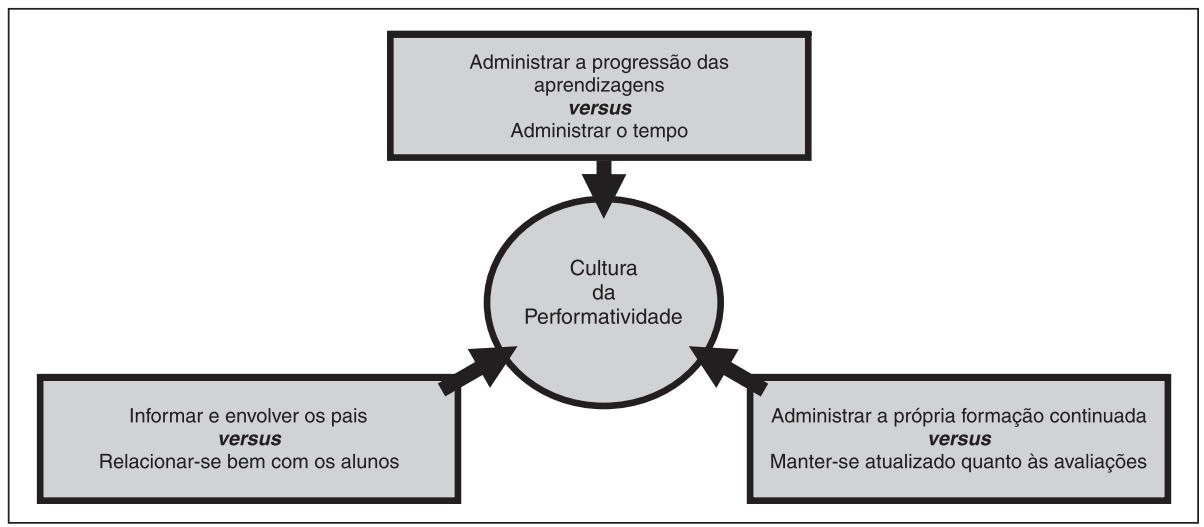

Figura 1 - Algumas competências consideradas relevantes pela escola e as relações que se podem fazer com as competências profissionais elencadas por Perrenoud

Constatamos, em quase todas as transcrições, a preocupação com os resultados dos estudantes e dos próprios professores. É evidente que não estamos questionando a busca por bons resultados em testes. O que verificamos é a supervalorização dessas ações, caracterizando uma espécie de obsessão pela obtenção dos conceitos máximos em todos os exames. Esse fato ressalta o peso da cultura da performatividade nas ações e nas decisões tomadas na instituição investigada.

Muitas vezes, seduzido pelo bom salário que recebe e pela valorização social que conquista, o professor que trabalha em tal instituição se rende ao culto ao desempenho, mesmo tendo sua prática e até suas convicções modeladas, deturpadas e aviltadas.

A escola investigada conquistou um ótimo desempenho no ENEM 2009. Ocorre que, para atingir esse objetivo, a ênfase na performatividade deixa para trás várias metodologias e resultados de pesquisa que a Educação Matemática trouxe nas últimas décadas, o que é de se esperar, já que os objetivos da instituição de ensino são completamente diferentes das visões sobre educação que as contribuições dos educadores matemáticos trazem.

A partir dessa oposição, configura-se um debate que precisa ser feito, a partir de questões como: que Educação Matemática queremos para os futuros estudantes? Prepará-los para testes? Para o mercado de trabalho? Para o prosseguimento dos estudos? Para a formação da cidadania? Isso se confunde com o próprio estatuto indefinido do ensino médio brasileiro e com os objetivos para a educação, mas seria recomendável que a Educação Matemática se posicionasse claramente sobre esses assuntos. 
A pesquisa em Educação Matemática sobre instituições com ótimo desempenho em avaliações em larga escala parece um campo promissor a ser investigado, porém ainda pouco explorado.

Esperamos que a leitura deste artigo suscite novas pesquisas em escolas que, por um lado são consideradas pela sociedade como sendo de excelência, mas, por outro lado estão à margem das discussões educacionais contemporâneas.

Talvez, a exposição dessa incoerência leve à reflexão sobre a necessidade de reformular os objetivos de avaliações em larga escala como o ENEM e, consequentemente, modifique o enfoque do próprio objetivo do ensino médio brasileiro que, pelo menos para a elite investigada por nós, parece caminhar cada vez mais em direção a uma educação propedêutica.

\section{Referências}

BALL, S. Perfomatividade, privatização e o pós-estado do bem-estar. Educação \& Sociedade, Campinas, v. 25, n. 89, p. 1105-1126, set./dez. 2004.

BALL, S. Profissionalismo, Gerencialismo e Performatividade. Cadernos de Pesquisa, São Paulo, v. 35, n. 126, p. 539-564, set./dez. 2005.

BOGDAN, R. C.; BIKLEN, S. K. Investigação qualitativa em educação: uma introdução à teoria e aos métodos. Tradução: Maria João Alvarez, Sara Bahia dos Santos e Telmo Mourinho Baptista. Porto: Porto Editora, 1994.

DIAS, R. E.; LOPES, A. C. Competências na formação de professores no Brasil: o que (não) há de novo. Educação \& Sociedade, Campinas, v. 24, n. 85, p. 1155-1177, dez. 2003.

FIORENTINI, D.; LORENZATO, S. Investigação em Educação Matemática: percursos teóricos e metodológicos. 2.ed. Campinas: Autores Associados, 2007.

LOPES, A. C.; MACEDO, E. F. Teorias de Currículo. São Paulo: Cortez, 2011.

NETO, V. F. Competências profissionais de professores de Matemática do ensino médio valorizadas por uma "boa" escola: a supremacia da cultura da performatividade. 2011. 159 f. Dissertação (Mestrado em Educação Matemática) Centro de Ciências Exatas e Tecnologia, Universidade Federal de Mato Grosso do Sul, Campo Grande, 2011.

PERRENOUD. P. Dez Novas Competências para Ensinar. Tradução: Patrícia Chittoni Ramos. Porto Alegre: Artmed, 2000. 
PERRENOUD, P. et al. Formando Professores Profissionais: Três conjuntos de questões. In: PERRENOUD, P. et. al. (Orgs.) Formando professores profissionais: quais estratégias? Quais competências? Tradução: Fátima Murad e Eunice Gruman. Porto Alegre: Artmed, 2001. p. 11-22.

PERRENOUD, P. A formação dos professores no século XXI. In: PERRENOUD P.; THURLER M. C. (Orgs.) As competências para ensinar no século XXI. Porto Alegre: Artmed, 2002. p.11-34.

SACRISTÁN, J. G. et al.Educar por competências: o que há de novo? Porto Alegre: Artmed, 2011.

SANTOS, L. L.C.P. Formação de Professores na Cultura do Desempenho. Educação \& Sociedade, Campinas, v. 25, n. 89, p. 1145-1157, set./dez. 2004.

YIN, R. K. Estudo de caso: Planejamento e Métodos. 3.ed. Porto Alegre: Bookman, 2005.

YIN, R. K. Qualitative Research from Start to Finish. New York: The Guilford Press, 2011.

Submetido em Abril de 2012. Aprovado em Julho de 2012. 